\title{
Hemodynamic Stability of the Patients Receiving Intravenous Dexmedetomidine versus Intravenous Propofol Based Sedation in Cervical Disc Surgeries
}

\author{
Padma S', Bhaskar Babu BD ${ }^{2}$ \\ ${ }^{1}$ Assistant Professor, Department of Anesthesiology, Sapthagiri Institute of Medical Science and Research center, Bengaluru, Karnataka, ${ }^{2}$ Associate \\ Professor, Department of Anesthesiology, Sapthagiri Institute of Medical Science and Research center, Bengaluru, Karnataka.
}

\section{Abstract}

Background: The sedative effect of dexmedetomidine is exercised subcortically and mimics natural sleep. The area of the brain with the highest concentration of alpha2-ARs is the locus coeruleus (LC) in the upper brainstem, which is responsible for arousal, sleep, anxiety, and withdrawal symptoms from drug addiction. It projects into two areas in the thalamus: the ventrolateral preoptic nucleus and the tuberomamillary nucleus. When the alpha2-AR is activated, it inhibits adenylyl cyclase. This results in the reduction of cAMP, with net efflux of $\mathrm{K}+$ (through $\mathrm{Ca} 2+$-activated $\mathrm{K}+$ channels) and inhibition of $\mathrm{Ca} 2+$ entry into nerve terminals. This hyperpolarises the neuron and suppresses the release of noradrenaline (NA) from the LC. Subjects and Methods: In this prospective study hundred ASA Grades I and II patients between the ages of 20 and 60 years undergoing elective cervical disc surgeries were enrolled after Ethical committee and Scientific committee approval meeting the below selection criteria. Results: The intergroup variation in the SBP during the intubation and till 5 mins after intubation showed a significant lower values in patients with the dexmedetomidine as compared with the propofol (P < 0.001$)$. Conclusion: Patients on dexmedetomidine had significantly better hemodynamic response to Fiberoptic bronchoscopy and intubation compared to propofol group. Heart rate, systolic, diastolic and mean arterial pressures were significantly lower in dexmedetomidine group as compared to propofol group during intubation and at various intervals post intubation.

Keywords: Hemodynamic stability, Dexmedetomidine, Propofol.

Corresponding Author: Dr. Bhaskar Babu BD, Associate Professor, Department of Anesthesiology, Sapthagiri Institute of Medical Science and Research center, Bengaluru, Karnataka.

Received: June 2019

Accepted: June 2019

\section{Introduction}

Dexmedetomidine is the dextro-stereoisomer and active ingredient of medetomidine, an agent used for many years in veterinary anaesthesia. It has a seven to eight-fold higher affinity for the alpha2-AR than clonidine. Alpha2-ARs are found ubiquitously in the central, peripheral and autonomic nervous systems, as well as in vital organs and blood vessels. Receptor activation leads to inhibition of noradrenaline release or hyperpolarisation. ${ }^{[1]}$

The initiation for the use of $\alpha 2$ agonists in anesthesia resulted from observations made in patients during anesthesia who were receiving clonidine therapy. Dexmedetomidine was introduced in clinical practice in the United States in 1999. It was approved by the FDA only as a short-term ( $<24$ hours) sedative for mechanically ventilated adult ICU patients. Dexmedetomidine is now being used off-label outside of the ICU in various settings. ${ }^{[2]}$

It is a highly selective and potent $\alpha 2$-adrenergic agonist. It shows a high ratio of specificity for the $\alpha 2$ receptor $(\alpha 2 / \alpha 1$ 1600:1) compared with clonidine ( $\alpha 2 / \alpha 1200: 1)$, making it a complete $\alpha 2$ agonist. Dexmedetomidine belongs to the imidazole subclass of $\alpha 2$ receptor agonists, similar to clonidine. It is freely soluble in water. ${ }^{[3]}$

Dexmeditomidine has rapid redistribution half life - 6 min. Dexmedetomidine is $94 \%$ protein bound, and its concentration ratio between whole blood and plasma is 0.66 . Biotransformation by conjugation (41\%), n-methylation $(21 \%)$, or hydroxylation followed by conjugation in liver. The inactive metabolites excreted in urine and feces. The elimination half-life of Dexmedetomidine is 2 to 3 hours, with a context- sensitive half-time ranging from 4 minutes after a 10-minute infusion to 250 minutes after an 8-hour infusion. No accumulation after infusions 12-24 h. Pharmacokinetics similar in young adults and elderly.

No significant drug interactions with other highly proteinbound drugs. It is recommended to reduce the dosage administered in patients with severe liver failure and endstage renal disease. Oral bioavailability is poor, owing to an extensive first-pass effect. However, bioavailability of dexmedetomidine administered sublingually is high (84\%), offering a potential role in pediatric sedation and premedication. ${ }^{[4]}$ 
0

A selective $\alpha 2$-adrenoceptor agonist. It's action is unique and different. Three subtypes of $\alpha 2$ adrenoreceptors have been described in humans: $\alpha 2 \mathrm{~A}, \alpha 2 \mathrm{~B}$, and $\alpha 2 \mathrm{C}$. The $\alpha 2 \mathrm{~A}$ adrenoreceptors are primarily distributed in the periphery, whereas $\alpha 2 \mathrm{~B}$ and $\alpha 2 \mathrm{C}$ are in the brain and spinal cord.

The overall response to $\alpha 2$ adrenoreceptors agonists is related to the stimulation of $\alpha 2$ adrenoreceptors located in the CNS and spinal cord. The $\alpha 2$ agonists produce their sedativehypnotic effect by an action on $\alpha 2$ receptors in the locus caeruleus and an analgesic action at $\alpha 2$ receptors within the locus caeruleus and within the spinal cord.

The sedative effect of dexmedetomidine is exercised subcortically and mimics natural sleep. The area of the brain with the highest concentration of alpha2-ARs is the locus coeruleus (LC) in the upper brainstem, which is responsible for arousal, sleep, anxiety, and withdrawal symptoms from drug addiction. It projects into two areas in the thalamus: the ventrolateral preoptic nucleus and the tuberomamillary nucleus. When the alpha2-AR is activated, it inhibits adenylyl cyclase. This results in the reduction of cAMP, with net efflux of $\mathrm{K}+$ (through $\mathrm{Ca} 2+$-activated $\mathrm{K}+$ channels) and inhibition of $\mathrm{Ca} 2+$ entry into nerve terminals. This hyperpolarises the neuron and suppresses the release of noradrenaline (NA) from the LC.

In the awake state, the release of NA from the LC inhibits the ventrolateral preoptic nucleus (VLPO). The VLPO, in turn, releases less $\gamma$-aminobutyric acid (GABA) and galanin to inhibit the tuberomammilary nucleus (TMN). The TMN is then free to release histamine, which binds to histamine receptors in the cortex and subcortical areas, producing the awake state.

During normal non-REM sleep or with alpha2-receptor activation, reduced noradrenergic inhibitory control over the VLPO results in an increased release of GABA and galanin which, in turn, inhibits the TMN release of histamine into the cortex and subcortical areas. This final effect of reduced histamine receptor occupancy is thought to produce the hypnotic state. ${ }^{[5]}$

The central hypnotic effect of dexmedetomidine, therefore, does not directly involve the GABA system and, consequently, does not cause cognitive impairment or disinhibition, as can propofol or benzodiazepines. Patients are calm and easily roused from sleep with good communication and performance of complex tasks, and they can then return to sleep.

Dexmedetomidine in animal models of incomplete cerebral ischemia and reperfusion reduces cerebral necrosis and improves neurologic outcome by reducing the intracerebral catecholamine outflow and the reduction of the excitatory neurotransmitter glutamate during injury.

Dexmedetomidine has been used in neurosurgical procedures involving neurophysiologic monitoring. Cortical evoked potentials amplitudes and latencies were minimally affected when using dexmedetomidine intraoperatively when patients underwent craniotomies. Dexmedetomidine increased growth hormone secretion in a dose-dependent manner, but it had no effect on other pituitary hormones. Dexmedetomidine ablates memory in a dose-dependent manner. Dexmedetomidine also is able to reduce muscle rigidity after high-dose opioid administration.

Dexmedetomidine at concentrations producing significant sedation reduces minute ventilation, but retains hypercapnic ventilatory response. Respiratory rate increased with increasing concentration from 14 breaths/min to 25 breaths/min. The changes in ventilation appeared similar to those observed during natural sleep. Dexmedetomidine has been implicated in blocking histamine-induced bronchoconstriction in dogs. ${ }^{[6]}$

The basic effects of $\alpha 2$ agonists on the cardiovascular system are decreased heart rate; decreased systemic vascular resistance; and indirectly decreased myocardial contractility, cardiac output, and systemic blood pressure.

The hemodynamic effects of a bolus of Dexmedetomidine in humans have shown a biphasic response. An acute IV injection of $2 \mu \mathrm{g} / \mathrm{kg}$ resulted in an initial increase in blood pressure $(22 \%)$ and decrease in heart rate $(27 \%)$ from baseline that occurred at 5 minutes after injection (probably due to the vasoconstrictive effects of dexmedetomidine when stimulating peripheral $\alpha 2$ receptors) followed by Heart rate return to baseline by 15 minutes, and blood pressure decrease $15 \%$ below baseline by 1 hour.

The incidence of hypotension and bradycardia may be related to the administration of a loading dose. Omitting the loading dose or not giving more than $0.4 \mu \mathrm{g} / \mathrm{kg}$ reduces the incidence of hypotension. Giving the loading dose over 20 minutes also minimizes the transient hypertension. ${ }^{[6]}$

\section{Subjects and Methods}

In this prospective study hundred ASA Grades I and II patients between the ages of 20 and 60 years undergoing elective cervical disc surgeries were enrolled after Ethical committee and Scientific committee approval meeting the below selection criteria.

\section{Inclusion Criteria:}

1. Age: $20-60$ years.

2. ASA grade: I / II.

3. Cervical disc patients.

4. Elective surgery

\section{Exclusion Criteria:}

1. Clinically significant neurologic, cardiovascular, renal, hepatic, or gastrointestinal diseases

2. Heart block $>$ first degree or heart rate $<50$ beats / minute

3. A history of alcohol or drug abuse (e.g. Opioids )

4. Known allergy, sensitivity, asthma, contraindications to any study drug.

5. Current h/o psychiatric disorder or presently on psychotropic medications

6. Pregnancy

Written consent from the patients involved in the study was taken. Patients were randomly distributed into two groups using computer generated random table.

Study Group - D (Dexmedetomidine): Fifty patients received intravenous dexmedetomidine. Dexmedetomidine was given as loading dose of $1 \mathrm{mcg} / \mathrm{kg}$ over 10 minutes and maintenance dose of $0.5 \mathrm{mcg} / \mathrm{kg}$ until the endotracheal was secured.

Control Group - P (Propofol): Fifty Patients received 
intravenous propofol. Propofol was given undiluted as a bolus dose of $1 \mathrm{mg} / \mathrm{kg}$ over $5 \mathrm{mins}$ followed by $0.5 \mathrm{mg} / \mathrm{kg}$ until tube was secured.

\section{Results}

The hemodynamic parameters taken into consideration were the blood pressure (systolic, diastolic and the mean) and heart rate. The results obtained are given below as tables and graphs which compare the difference between the mean values of the parameters at Baseline ,5 minutes after sedation bolus dose , 30 seconds, 60 seconds, 90 seconds, 120 seconds , 150 seconds 180 seconds , 4 minutes and 5 minutes after intubation.

Haemodynamic variables measured immediately after wheeled to operating room was taken as 'baseline' values. In dexmedetomidine group, the baseline values were SBP $133.16 \pm 11.92 \mathrm{mmHg}$; DBP $83.62 \pm 7.02 \mathrm{mmHg}$; and $\mathrm{MBP}$ $100.14 \pm 7.80 \mathrm{mmHg}$ and $\mathrm{HR} 76.40 \pm 8.51 \mathrm{bpm}$. In propofol group, the baseline values were SBP $-132.04 \pm 13.51 \mathrm{mmHg}$; DBP $83.50 \pm 8.46 \mathrm{mmHg}$; and MBP $99.64 \pm 9.30 \mathrm{mmHg}$ and HR $78.52 \pm 6.89 \mathrm{bpm}$. There was no statistically significant difference between the two groups with respect to $\mathrm{SBP}(\mathrm{P}=$ $0.661)$, DBP $(\mathrm{P}=0.939), \mathrm{MBP}(\mathrm{P}=0.771)$ and $\mathrm{HR}(\mathrm{P}=$ $0.174)$.

HR is comparable between both the groups at baseline, after 5 minutes of bolus infusion there is statistically significant fall in heart rate from the baseline values in dexmedetomidine (study) group $(68.60 \pm 7.28)$ compared to propofol (control) group (77.72 \pm 8.69$)$. There is statistically significant increase in heart rate during intubation with control group $(86.60 \pm 10.84)$ compared to study group $(71.08 \pm 8.33)$ with $\mathrm{p}$ value $<0.001 * *$. There were statistically significant differences $(\mathrm{P}<0.001 * *)$ between the groups with respect to changes in HR, at various points of time after intubation. Mean heart rate remained lower than baseline

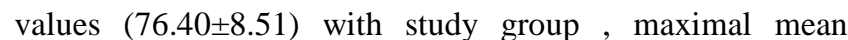
decrease in heart rate with study group is $65.52 \pm 6.18$ at 5 mins after intubation, none of the patients had bradycardia $(\mathrm{HR}<50)$ with study group, where as with control group $(\mathrm{P})$ maximum mean decrease in heart rate is $75.70 \pm 8.59$ at 5 mins after intubation, mean increase in heart rate from baseline is $86.60 \pm 10.84$ during intubation, $\mathrm{HR}$ reached baseline values at 120 secs and remained lower after that.

Table 1: Comparison of Heart rate (bpm) in two groups of patients studied.

\begin{tabular}{|l|l|l|l|}
\hline $\begin{array}{l}\text { Heart } \\
\text { rate(bpm) }\end{array}$ & $\begin{array}{l}\text { Study(D) } \\
\text { group }\end{array}$ & $\begin{array}{l}\text { Control(P) } \\
\text { group }\end{array}$ & P value \\
\hline Baseline & $76.40 \pm 8.51$ & $78.52 \pm 6.89$ & 0.174 \\
\hline $\begin{array}{l}5 \text { min after } \\
\text { Bolus Infusion }\end{array}$ & $68.60 \pm 7.28$ & $77.72 \pm 8.69$ & $<0.001^{* *}$ \\
\hline $\begin{array}{l}\text { During } \\
\text { Intubation }\end{array}$ & $71.08 \pm 8.33$ & $86.60 \pm 10.84$ & $<0.001^{* *}$ \\
\hline At 30 sec & $70.30 \pm 8.32$ & $84.00 \pm 10.82$ & $<0.001^{* *}$ \\
\hline At 60 sec & $69.16 \pm 8.12$ & $81.20 \pm 10.19$ & $<0.001^{* *}$ \\
\hline At 90 sec & $67.58 \pm 6.88$ & $79.86 \pm 10.07$ & $<0.001^{* *}$ \\
\hline At 120 sec & $67.00 \pm 7.02$ & $78.60 \pm 10.04$ & $<0.001^{* *}$ \\
\hline At 150 sec & $66.20 \pm 6.70$ & $77.64 \pm 9.77$ & $<0.001^{* *}$ \\
\hline At 180 sec & $66.36 \pm 6.50$ & $77.02 \pm 9.08$ & $<0.001^{* *}$ \\
\hline At 4 mins & $65.94 \pm 6.23$ & $76.50 \pm 8.53$ & $<0.001^{* *}$ \\
\hline At 5 mins & $65.52 \pm 6.18$ & $75.70 \pm 8.59$ & $<0.001^{* *}$ \\
\hline
\end{tabular}

At baseline, SBP in both the groups were comparable. There were significant differences between the groups with respect to changes in SBP, at various points of time after intubation. The rise in SBP at the time of intubation was significantly higher in the propofol group $141.73 \pm 13.35 \mathrm{mmHg}$ compared to dexmedetomidine group $126.42 \pm 10.41 \mathrm{mmHg}$ with $\mathrm{p}$ $<0.001$. The SBP remained lower than baseline after 5 mins of bolus infusion till 5 mins post intubation in study group, where as SBP in control group decreased from the baseline value after 5 mins of bolus infusion $(132.04 \pm 13.51$ vs. $125.40 \pm 11.57)$ but there was significant increase in SBP during intubation from the baseline $141.73 \pm 13.35$ vs. $132.04 \pm 13.51$, started to lower and reached close to baseline values by 60 seconds and remained so thereafter till 5 minutes after intubation. The intergroup variation in the SBP during the intubation and till 5 mins after intubation showed a significant lower values in patients with the dexmedetomidine as compared with the propofol $(\mathrm{P}<$ $0.001)$.

Table 2: Comparison of SYSTOLIC BLOOD PRESSURE in two groups of patients studied.

\begin{tabular}{|l|l|l|l|}
\hline $\begin{array}{l}\text { Systolic Blood } \\
\text { Pressure }\end{array}$ & Study group & Control group & P value \\
\hline Baseline & $133.16 \pm 11.92$ & $132.04 \pm 13.51$ & 0.661 \\
\hline $\begin{array}{l}5 \text { min after } \\
\text { Bolus Infusion }\end{array}$ & $126.90 \pm 10.92$ & $125.40 \pm 11.57$ & 0.561 \\
\hline $\begin{array}{l}\text { During } \\
\text { Intubation }\end{array}$ & $126.42 \pm 10.41$ & $141.73 \pm 13.35$ & $<0.001^{* *}$ \\
\hline At 30 sec & $125.24 \pm 9.95$ & $136.98 \pm 13.57$ & $<0.001^{* *}$ \\
\hline At $60 \mathrm{sec}$ & $123.04 \pm 10.02$ & $132.63 \pm 13.83$ & $<0.001^{* *}$ \\
\hline At $90 \mathrm{sec}$ & $120.82 \pm 9.74$ & $131.00 \pm 14.16$ & $<0.001^{* *}$ \\
\hline At $120 \mathrm{sec}$ & $119.48 \pm 9.77$ & $129.02 \pm 14.25$ & $<0.001^{* *}$ \\
\hline At $150 \mathrm{sec}$ & $118.68 \pm 9.51$ & $127.82 \pm 14.09$ & $<0.001^{* *}$ \\
\hline At $180 \mathrm{sec}$ & $117.00 \pm 9.81$ & $125.94 \pm 13.76$ & $<0.001^{* *}$ \\
\hline At $4 \mathrm{mins}$ & $115.44 \pm 10.22$ & $124.55 \pm 13.84$ & $<0.001^{* *}$ \\
\hline At 5 mins & $113.96 \pm 9.73$ & $122.06 \pm 12.82$ & $0.001^{* *}$ \\
\hline A $5 \mathrm{~ms}$ & &
\end{tabular}

At 5 mins, it is highly significant

If $\mathrm{P}$ value attains less than $0.01(1 / 100)$ is enough to claim high significance, here it is $0.001(1 / 1000)$

Baselines DBP in both the groups were comparable. There is decrease in DBP in both the groups from the baseline but the mean fall in DBP was lower in the propofol group $76.74 \pm 6.99$ as compared to the dexmedetomidine group $79.20 \pm 7.94$ after 5 mins of bolus infusion. There were significant fall in DBP in dexmedetomidine group at various points of time after intubation, and during intubation compared to propofol.

Table 3: Comparison of DIASTOLIC BLOOD PRESSURE in two groups of patients studied

\begin{tabular}{|l|l|l|l|}
\hline $\begin{array}{l}\text { Diastolic Blood } \\
\text { Pressure }\end{array}$ & Study (D)group & $\begin{array}{l}\text { Control(P) } \\
\text { group }\end{array}$ & P value \\
\hline Baseline & $83.62 \pm 7.02$ & $83.50 \pm 8.46$ & 0.939 \\
\hline $\begin{array}{l}5 \text { min after Bolus } \\
\text { Infusion }\end{array}$ & $79.20 \pm 7.94$ & $76.74 \pm 6.99$ & 0.103 \\
\hline During Intubation & $79.36 \pm 7.80$ & $87.10 \pm 8.42$ & $<0.001^{* *}$ \\
\hline At 30 sec & $77.52 \pm 6.54$ & $84.12 \pm 8.50$ & $<0.001^{* *}$ \\
\hline At 60 sec & $76.00 \pm 6.24$ & $81.59 \pm 9.17$ & $0.001^{* *}$ \\
\hline At 90 sec & $74.60 \pm 6.15$ & $80.45 \pm 9.15$ & $<0.001^{* *}$ \\
\hline At $120 \mathrm{sec}$ & $73.36 \pm 5.74$ & $79.16 \pm 9.32$ & $<0.001^{* *}$ \\
\hline At $150 \mathrm{sec}$ & $72.78 \pm 5.79$ & $78.39 \pm 9.54$ & $0.001^{* *}$ \\
\hline At $180 \mathrm{sec}$ & $71.12 \pm 6.01$ & $76.94 \pm 9.49$ & $<0.001^{* *}$ \\
\hline At $4 \mathrm{mins}$ & $70.10 \pm 5.79$ & $76.04 \pm 9.18$ & $<0.001^{* *}$ \\
\hline At 5 mins & $68.86 \pm 5.40$ & $74.29 \pm 8.46$ & $<0.001^{* *}$ \\
\hline
\end{tabular}


At baseline, MAP in both the groups were comparable. There were significant differences between the groups with respect to changes in MAP, at various points of time after intubation. There is decrease in MAP in both the groups from the baseline but the fall in MAP was lower in the propofol group 93.00 \pm 7.74 as compared to the dexmedetomidine group $95.10 \pm 8.28$ after 5 mins of bolus infusion. There were significant fall in MAP in dexmedetomidine group at various points of time after intubation compared to propofol, but statistically more significant fall during intubation $(95.02 \pm 7.46$ vs. $103.22 \pm 17.53)$ ( $\mathrm{P}$ value $\left.-0.003^{* *}\right)$

\section{Discussion}

Yildiz $\mathrm{M}$ et al did study to evaluate the effect of a single preinduction intravenous dose of dexmedetomidine $1 \mathrm{microg} / \mathrm{kg}$ on cardiovascular response resulting from laryngoscopy and endotracheal intubation, need for anaesthetic agent and perioperative haemodynamic stability. Fifty patients scheduled for elective minor surgery were randomised into two groups (dexmedetomidine group and placebo group, $\mathrm{n}=$ 25 in each group). Fentanyl $1 \mathrm{microg} / \mathrm{kg}$ was administered to all patients and thiopental was given until lash reflex disappeared. Anaesthesia continuation was maintained with $50 \%$ : $50 \%$, oxygen : nitrous oxide. Sevoflurane concentration was adjusted to maintain systolic blood pressure within $20 \%$ of preoperative values. Haemodynamic parameters and adverse effects were recorded every 10 minutes for 1 hour after surgery. They found that preoperative administration of a single dose of dexmedetomidine resulted in progressive increases in sedation, blunted the haemodynamic responses during laryngoscopy, and reduced opioid and anaesthetic requirements. Furthermore, dexmedetomidine decreased blood pressure and heart rate as well as the recovery time after the operation. ${ }^{[7]}$

Uysal HY, Tezer E, Türkoğlu M, Aslanargun P, Başar H, conducted study in order to compare the effects of dexmedetomidine on hemodynamic response to tracheal intubation in hypertensive patients with esmolol and sufentanyl. Sixty hypertensive patients scheduled for noncardiac surgery under general anesthesia were randomly assigned to receive one of the three drugs before induction of anesthesia. Groups I, II, and III respectively received esmolol $(100 \mathrm{mg})$ dexmedetomidine $(1 \mu \mathrm{g} / \mathrm{kg})$ and sufentanyl $(0.25$ $\mu \mathrm{g} / \mathrm{kg}$ ). Heart Rate (HR), systolic (SAP) and diastolic (DAP) arterial pressures were recorded before drug administration (baseline; T1), after drug administration (T2), after induction of anesthesia (T3), immediately after intubation (T4) and 3, 5 and 10 minutes after intubation (T5, T6, and T7, respectively). In hypertensive patients, administration of dexmedetomidine before anesthesia induction blunts the hemodynamic response to tracheal intubation and reduces the thiopental dose. ${ }^{[8]}$

Menda $\mathrm{F}$ et al did a prospective, randomized study, in which dexmedetomidine has been used to attenuate the hemodynamic response to endotracheal intubation with low dose fentanyl and etomidate in patients undergoing myocardial revascularization receiving beta blocker treatment. Thirty patients undergoing myocardial revascularization received in a double blind manner, either a saline placebo or a dexmedetomidine infusion ( $1 \mathrm{microg} / \mathrm{kg}$ ) before the anesthesia induction. Heart rate (HR) and blood pressure (BP) were monitored at baseline, after placebo or dexmedetomidine infusion, after induction of general anesthesia, one, three and five minutes after endotracheal intubation. The incidence of tachycardia, hypotension and bradycardia was not different between the groups. The incidence of hypertension requiring treatment was significantly greater in the placebo (PLA) group. It is concluded that dexmedetomidine can safely be used to attenuate the hemodynamic response to endotracheal intubation in patients undergoing myocardial revascularization receiving beta blockers. ${ }^{[9]}$

Kunisawa T, Nagata O, Nagashima M.et al did a Prospective, double-blinded, randomized study on 30 ASA physical status II and III patients with mild-to-moderate cardiovascular disease ,to evaluate the effect of dexmedetomidine combined with fentanyl on hemodynamics. Patients were assigned to one of three groups: Group D-F2 [dexmedetomidine, effectsite concentration $(\mathrm{ESC})$ of fentanyl = two $\mathrm{ng} / \mathrm{mL}$ ]; Group F2 (placebo, ESC of fentanyl = two $\mathrm{ng} / \mathrm{mL}$ ), or Group $\mathrm{F} 4$ (placebo, ESC of fentanyl $=4 \mathrm{ng} / \mathrm{mL}$ ). They concluded that Dexmedetomidine combined with fentanyl during anesthetic induction suppresses the decrease in blood pressure due to anesthetic induction and also blunts the cardiovascular response to tracheal intubation. ${ }^{[10]}$

Hogue CW Jr, Talke P, Stein PK, Richardson C, et al did a prospectively randomized, double-blinded crossover study design in volunteers who received either placebo or low- or high-dose dexmedetomidine (target plasma concentrations 0.3 or $0.6 \mathrm{ng} / \mathrm{ml}$, respectively) infusions. To determine the effects of dexmedetomidine on systemic and cardiac autonomic reflex responses during rest and during thermal stress .Concluded that infusion of dexmedetomidine results in compensated reductions in systemic sympathetic tone without changes in baroreflex sensitivity. Dexmedetomidine blunts heart rate and the systemic sympathetic activation due to sweating, but it is less effective in blunting cardiac sympathetic responses to shivering. During dexmedetomidine infusion, cardiac sympathetic and parasympathetic tone may have nonreciprocal changes during shivering. ${ }^{[11]}$

Kato J, Ogawa Y, Kojima W, Aoki K, Ogawa S did a double-blind, randomized, and placebo-controlled study. Twelve healthy men received placebo, low-dose (loading 3 microg $\mathrm{kg}(-1) \mathrm{h}(-1)$ for $10 \mathrm{~min}$; maintenance 0.2 microg $\mathrm{kg}(-$ 1) $\mathrm{h}(-1)$ for $60 \mathrm{~min})$, and moderate-dose (loading 6 microg $\mathrm{kg}(-1) \mathrm{h}(-1)$ for $10 \mathrm{~min}$; maintenance 0.4 microg $\mathrm{kg}(-1) \mathrm{h}(-1)$ for $60 \mathrm{~min})$ dexmedetomidine infusions. After $70 \mathrm{~min}$ of drug infusion, systolic arterial pressure (SAP) and HR responses after thigh cuff deflation were evaluated as indices of cardiovascular reflex. Concluded that dexmedetomidine weakens arterial pressure preservation and HR responses after thigh cuff deflation, suggesting attenuated cardiovascular reflexes. Therefore, it must be cautioned that dexmedetomidine can lead to further and sustained reduction in arterial pressure during transient hypotension induced by postural changes, hemorrhage, and/or other stresses. ${ }^{[12]}$

Rong Hu, J. X. Liu, Hong Jiang et al did a double-blinded randomized controlled trial comparing Dexmedetomidine 
versus remifentanil sedation during awake Fiberoptic nasotracheal intubation in Forty patients received either dexmedetomidine $(n=20)$ or remifentanil $(n=20)$. Primary outcome measures were endoscopy, intubation, and postintubation conditions as scored by the attending anesthesiologist. Other parameters included the time taken to achieve the desired level of sedation, endoscopy time, intubation time, and hemodynamic changes during the procedure. An interview was conducted $24 \mathrm{~h}$ after surgery to evaluate patients' recall of and satisfaction with the procedure. They concluded that Both dexmedetomidine and remifentanil were effective as sedatives in patients undergoing awake Fiberoptic nasotracheal intubation. Compared with remifentanil, dexmedetomidine offered better endoscopy scores, lower recall of intubation, and greater patient satisfaction, with minor hemodynamic side effects. $^{[13]}$

Bergese SD, Patrick Bender S, McSweeney TD , Fernandez et al did Randomized, double-blinded study to evaluate the efficacy of dexmedetomidine with midazolam (DEX-MDZ) versus midazolam only (MDZ) for sedation during awake Fiberoptic intubation (AFOI). All patients received intravenous (IV) glycopyrrolate $0.2 \mathrm{mg}$ premedication, oxygen by nasal cannula, and topical local anesthetics to the airway. MDZ subjects received IV midazolam $0.05 \mathrm{mg} / \mathrm{kg}$ with additional doses to achieve a Ramsay Sedation Scale (RSS) score of >or= 2. DEX-MDZ patients received midazolam $0.02 \mathrm{mg} / \mathrm{kg}$ followed by dexmedetomidine one $\mathrm{microg} / \mathrm{kg}$, then an infusion of dexmedetomidine 0.1 microg $/ \mathrm{kg} / \mathrm{hr}$ and titrated to $0.7 \mathrm{microg} / \mathrm{kg} / \mathrm{hr}$ to achieve RSS>or=2. DEX-MDZ patients were significantly calmer and more cooperative during AFOI and had fewer adverse reactions to $\mathrm{AFOI}$ than did the MDZ patients. There were no significant hemodynamic differences between the two subject groups. Concluded that Dexmedetomidine in combination with low doses of midazolam is more effective than midazolam alone for sedation in AFOI. ${ }^{[14]}$

Yakup Üstün, Murat Gündüz,et al, did a double-blind, crossover, randomized study to compare the use of dexmedetomidine with the use of midazolam during intravenous conscious sedation in impacted mandibular third molar surgery. Either dexmedetomidine (group D) $(4 \mu \mathrm{g}$. $\mathrm{kg}-1 \cdot \mathrm{h}-1)$ or midazolam (group M) $(0.4 \mathrm{mg} \cdot \mathrm{kg}-1 \cdot \mathrm{h}-1)$ was administered intravenously for 15 minutes before the first operation. At the second operation, the other agent was applied. The mean heart rate and blood pressure measurements were significantly lower in group D. There was no significant difference in the respiratory findings. They concluded that Dexmedetomidine may be a remarkable alternative to midazolam for intravenous sedation because it seems to be a reliable and safe method, with additional analgesic effect providing a satisfactory sedation level without any serious side effects during impacted third molar surgery. ${ }^{[15]}$

M. G. Irwin et al did a study to evaluate Patient-maintained propofol sedation using target-controlled infusion system . Thirty-six Chinese patients scheduled to undergo local and regional anaesthesia were entered into the study. An intravenous propofol infusion was started at a target plasma level of $1 \mathrm{mg} \cdot \mathrm{ml}^{11}$. The patient was able to increase the target propofol concentration in $0.2-\mathrm{mg}_{\mathrm{ml}} \mathrm{m}^{1} 1$ increments by pressing a demand button. There was a lockout interval of 2 min and a maximum permissible target concentration of 3 mg.ml ${ }^{1} 1$. Sedation was evaluated using a modified Steward scoring system. Sedation assessments were recorded at 10min intervals following the start of the infusion along with the amount of propofol infused, the number of demands made, the target blood propofol concentration and the effect concentration. The infusion was terminated and disconnected from the patient when the surgeon indicated that the operative procedure was about to finish they found that Respiratory rate decreased with the onset of sedation and the lowest recorded rate was 10 breaths. $\min ^{1} 1$ but there were no instances of airway obstruction requiring intervention. They concluded that this technique combines the benefits of TCI with patient-controlled feedback and produces safe intraoperative sedation during regional anaesthesia with rapid recovery and high patient satisfaction. ${ }^{[16]}$

Higgins TL, Yared JP et al did Open, randomized, prospective trial to compare the safety and effectiveness of propofol (2,6-diisopropylphenol) to midazolam for sedation of mechanically ventilated patients after coronary artery bypass grafting. Eighty-four patients with normal or moderately impaired left ventricular function who underwent elective coronary artery bypass graft surgery under high-dose opioid anesthesia were randomly selected to receive either propofol (mean loading dose $0.24 \mathrm{mg} / \mathrm{kg}$; mean maintenance dose $0.76 \mathrm{mg} / \mathrm{kg} / \mathrm{hr}$ ) or midazolam (mean loading dose 0.012 $\mathrm{mg} / \mathrm{kg}$; mean maintenance dose $0.018 \mathrm{mg} / \mathrm{kg} / \mathrm{hr}$ ). Infusion rates were titrated to keep patients comfortable, drowsy, and responsive to verbal stimulation. Study duration, 8 to $12 \mathrm{hrs}$; infusions were started in the ICU when patients were awake and hemodynamically stable.concluded that. Both propofol and midazolam provided safe and effective sedation of coronary artery bypass graft patients recovering from highdose opioid anesthesia. The reduced need for both antihypertensive medication and opioids seen in the propofol group may be advantageous. ${ }^{[17]}$

Tsai et al did study to compare the effectiveness of dexmedetomidine versus target controlled propofol infusion in providing sedation during Fiberoptic intubation in Forty patients with anticipated difficult airways and due to undergo tracheal intubation for elective surgery were enrolled and randomly allocated into the dexmedetomidine group (1.0 lg.kg 1 over $10 \mathrm{~min})(\mathrm{n}=20)$ or the propofol target controlled infusion group $(n=20)$. Intubating conditions and patient tolerance as graded by a scoring system were evaluated as primary outcomes. Intubation was successful in all patients. Satisfactory intubating conditions were found in both groups (19/20 in each group). The dexmedetomidine group experienced fewer airway events and less heart rate response to intubation than the propofol group ( $p<0.003$ and $\mathrm{p}=0.007$, respectively). They concluded that both dexmedetomidine and propofol target-controlled infusion are effective for fibreoptic intubation. Dexmedetomidine allows better tolerance, more stable haemodynamic status and preserves a patent airway. ${ }^{[18]}$

\section{Conclusion}

The hemodynamic stability was evaluated by heart rate, 
0

systolic, diastolic and mean arterial pressures. Level of sedation was noted using modified steward score and respiratory depression was assessed by respiratory rate and oxygen saturation.

Patients on dexmedetomidine had significantly better hemodynamic response to Fiberoptic bronchoscopy and intubation compared to propofol group. Heart rate, systolic, diastolic and mean arterial pressures were significantly lower in dexmedetomidine group as compared to propofol group during intubation and at various intervals post intubation.

Dexmedetomidine provided adequate sedation where patients were in sleep like state and were easily arousable, cooperative and were following commands and there was minimal patient discomfort with no respiratory depression in any of the patient. We did not encounter any loss of airway or severe airway obstruction during intubation. The patients had excellent cooperation for post-intubation neurologic examination. Where as in Propofol group, few patients developed apnea, reduced respiratory rate (7-10 breaths /min) requiring frequent awakening. Some more patients (15) developed respiratory obstruction requiring jaw retraction.

However there were no episodes of desaturation, no change in post intubation conditions in any of the patients in both the groups. Successful intubation was done with both the groups except for 1 patient in propofol group who developed prolong cough and severe resistance who was considered failure and intubated under GA.

\section{References}

1. Nibedita Panil and Shovan Kumar Rath. Regional \& Topical Anaesthesia of Upper Airways. Indian J Anaesth. 2009 December; 53(6): 641-648.

2. Deem SA, Bishop MJ, Bedford RF. Physiologic And Pathophysiologic Responses To Intubation. In; Benumof's Airway Management: Principles and Practice 2nd Ed Mosby Elsevier pp 194

3. Guyton AQ. Nervous Regulation of circulation and rapid control of arterial pressure. In; Matin J Wonsiewicz, twxtbook of Physiology, 8th ed, WB Saunders Co. Prism Book Pvt Ltd, India : pp 194-197

4. Shribman AJ, Smith G, Achola KJ. Cardiovascular And Catecholamine Responses To Laryngoscopy With And Without Tracheal Intubation Br. J. Anaesth. 1987; 59 (3): 295-299

5. Hassan HG, el-Sharkawy TY, Renck H, et al Hemodynamic and catecholamine responses to laryngoscopy with vs. without endotracheal intubation. Acta Anaesthesiol Scand 35:442, 1991.

6. Martin Berry, Lawrence H. Bannister, Susan M. Nervous System, In: Peter Williams (ed), Gray's Textbook Of Anatomy, 38th ed, Churchill Livingstone, London, 1995, pp 1018

7. Yildiz M, Tavlan A, Tuncer S, Reisli R, Yosunkaya A, Otelcioglu S. Effect of dexmedetomidine on haemodynamic responses to laryngoscopy and intubation : perioperative haemodynamics and anaesthetic requirements. Drugs R D. 2006; 7(1):43-52.

8. Uysal HY, Tezer E, Türkoğlu M, Aslanargun P, Başar H. The effects of dexmedetomidine on hemodynamic responses to tracheal Intubation in hypertensive patients: A comparison with esmolol and sufentanyl. J Res Med Sci. 2012; 17 (1):22-31.

9. Menda F, Köner $O$, Sayin $M$, Türe $H$, Imer $P$, Aykaç $B$. Dexmedetomidine as an adjunct to anesthetic induction to attenuate hemodynamic response to endotracheal intubation in patients undergoing fast-track CABG. Ann Card Anaesth.2010;13 (1):16-21.

10. Kunisawa T, Nagata O, Nagashima M, Mitamura S, Ueno M, Suzuki A, Takahata O, Iwasaki H. Dexmedetomidine suppresses the decrease in blood pressure during anesthetic induction and blunts the cardiovascular response to tracheal intubation.J Clin Anesth. 2009;21 (3):194-9.

11. Hogue CW Jr, Talke P, Stein PK, Richardson C, Domitrovich PP, Sessler DI. Autonomic nervous system responses during sedative infusions of dexmedetomidine. Br J Anaesth. 2009;103 (4):561-5.

12. Kato J, Ogawa Y, Kojima W, Aoki K, Ogawa S, Iwasaki K. Cardiovascular reflex responses to temporal reduction in arterial pressure during dexmedetomidine infusion: a double-blind, randomized, and placebo-controlled study. Br J Anaesth. 2009 ;103 (4):561-5.

13. Rong Hu, J. X. Liu, Hong Jiang .Dexmedetomidine versus remifentanil sedation during awake fiberoptic nasotracheal intubation: a doubleblinded randomized controlled trial. Journal of Anesthesia . 2013; 27 ( 2): 211-217.

14. Bergese SD,Patrick Bender S,McSweeney TD,Fernandez S,Dzwonczyk R,Sage K, A comparative study of dexmedetomidine with midazolam and midazolam alone for sedation during elective awake fiberoptic intubation. J Clin Anesth. 2010;22 (1):35-40.

15. Yakup Üstün, Murat Gündüz,et, Özgür Erdoğan, Emre Benlidayi. Dexmedetomidine Versus Midazolam in Outpatient Third Molar Surgery.Journal of Oral and Maxillofacial Surgery. 2006; 64 (9): 13531358.

16. Irwin MG, Thompson N, Kenny GN. Patient Maintained propofol sedation. Assessment of a target -controlled infusion system, Anaesthesia 1997: 52:525-30.

17. Higgins TL, Yared JP, Estafanous FG, Coyle JP, Ko HK, Goodale DB. Propofol versus midazolam for intensive care unit sedation after coronary artery bypass grafting. Crit Care Med. 1994 Sep; 22(9): 141523.

18. Tsai CJ, Chu KS, Chen TI, Lu DV, Wang HM, Lu IC. A comparison of the effectiveness of dexmedetomidine versus propofol target-controlled infusion for sedation during fibreoptic nasotracheal intubation. Anaesthesia. 2010 ; 65(3):254-9.

Copyright: () the author(s), publisher. Academia Anesthesiologica International is an Official Publication of "Society for Health Care \& Research Development". It is an open-access article distributed under the terms of the Creative Commons Attribution Non-Commercial License, which permits unrestricted non-commercial use, distribution, and reproduction in any medium, provided the original work is properly cited.

How to cite this article: Padma S, Babu BDB. Hemodynamic Stability of the Patients Receiving Intravenous Dexmedetomidine versus Intravenous Propofol Based Sedation in Cervical Disc Surgeries. Acad. Anesthesiol. Int. 2019;4(2):33-38.

DOI: dx.doi.org/10.21276/aan.2019.4.2.9

Source of Support: Nil, Conflict of Interest: None declared. 